\title{
man \\ Disassembly Line Balancing of Electronic Waste Considering the Degree of Task Correlation
}

\author{
Chen-Yang Cheng ${ }^{1}$, Yin-Yann Chen ${ }^{2}$, Pourya Pourhejazy ${ }^{3, * \mathbb{D}}$ and Chih-Yu Lee ${ }^{2}$ \\ 1 Department of Industrial Engineering and Management, National Taipei University of Technology, \\ Taipei 10608, Taiwan; cycheng@ntut.edu.tw \\ 2 Department of Industrial Management, National Formosa University, Huwei 63201, Taiwan; \\ yyc@nfu.edu.tw (Y.-Y.C.); unice91065@gmail.com (C.-Y.L.) \\ 3 Department of Industrial Engineering, UiT The Arctic University of Norway, Lodve Langsgate 2, \\ 8514 Narvik, Norway \\ * Correspondence: pourya.pourhejazy@uit.no
}

check for updates

Citation: Cheng, C.-Y.; Chen, Y.-Y.; Pourhejazy, P.; Lee, C.-Y. Disassembly Line Balancing of Electronic Waste Considering the Degree of Task Correlation. Electronics 2022, 11, 533. https://doi.org/10.3390/ electronics11040533

Academic Editor: Nicu Bizon

Received: 12 January 2022

Accepted: 9 February 2022

Published: 10 February 2022

Publisher's Note: MDPI stays neutral with regard to jurisdictional claims in published maps and institutional affiliations.

Copyright: (C) 2022 by the authors. Licensee MDPI, Basel, Switzerland. This article is an open access article distributed under the terms and conditions of the Creative Commons Attribution (CC BY) license (https:// creativecommons.org/licenses/by/ $4.0 /)$.

\begin{abstract}
With growing concerns about the depletion of rare-earth elements, managing End-of-Life products has become a key sustainability initiative in the supply chains of global corporations. Recycling, the process of dismantling, separating, and recovery of components and raw materials from wastes, is technologically challenging and should be planned in such a way as to ensure operational efficiency as well as safety. This study explores the Disassembly Line Balancing Problem with Correlated Tasks (DLBP-CT), which is prevalent in the recycling of the Waste of Electrical and Electronic Equipment (WEEE). For this purpose, an original Integer Nonlinear Programming (INLP) model is proposed to find the optimal configuration for the disassembly lines. Given the NP-hard nature of this problem, the Adaptive Genetic Algorithm (AGA) is developed to solve the problem, minimizing the number of workstations and maximizing the relationship between the disassembly tasks. A case example from electronic waste is provided to test the practicality of the developed optimization approach. Sensitivity analysis is conducted to explore the impact of parameter changes in the optimization outcomes. Results are supportive of the applicability of the developed approach and show that it can serve as a strong decision aid tool when selecting the best disassembly process, workstations, and task assignments.
\end{abstract}

Keywords: waste management; recycling; Disassembly Line Balancing Problem; correlated tasks; optimization

\section{Introduction}

The rapid technological and economic development has changed consumer behavior, which, as a major result, shortened the lifecycle of electrical and electronic products. The exponential growth in the quantity of End-of-Life electronic items has made the Waste of Electrical and Electronic Equipment (WEEE) the fastest-growing waste stream [1,2], with an estimated annual growth of three to five percent [3]. WEEEs are hazardous; nevertheless, they can generate value with proper treatment through authorized recycling channels [4,5]. With the circular economy encouraging $R$-imperatives [6], proper disassembly of WEEE is of paramount importance for reducing the extraction of rare-earth elements [7], alleviating environmental problems $[8,9]$, reducing health risks caused by the use of certain hazardous substances [10-13], and bringing about financial benefits [14].

WEEE management is complex and requires various interventions and standardization in certain stages. Formal collection networks and informal collectors-i.e., waste pickers, waste merchants, and the middlemen-should cooperate with remanufacturing and recycling companies to maximize the reclaimable value of the collected products [5]. Remanufacturing and recycling companies extract valuable components and sub-components 
such that they can be reused, recycled, or discarded safely and soundly. The disassembly line is the best operational setting for the disassembly of products with a complex structure, large products with many components, and the small products received in large batches $[15,16]$. The dramatic increase in the volume of WEEE highlights the need for effective disassembly line balancing and modeling [17]. Since the emergence of the Disassembly Line Balancing Problem (DLBP; [18]), many extensions have been developed to address various operational situations through studying different line configurations, product types, disassembly depths, performance measures, technical requirements, and physical constraints [19]. The main objective of DLBPs is to satisfy the demand for recovered parts using the available resources. The vast majority of the line balancing studies are focused on reducing the operational cost $[17,20,21]$ and increasing revenue [22-24]. Additional operational/technical considerations and performance measures are required to improve the effectiveness and efficiency of the disassembly operations.

Given the limited profit margin in the recycling business, minimizing the operational cost is of critical importance [25]. Improving the utilization of resources to boost the efficiency of the operations is a major consideration with tangible economic implications. The extant literature well explored the tangible dimensions of this consideration-reconfiguring the layout to improve material flow [26], reducing the number of disassembly workstations [27-31], improving workload smoothness by making a balance between workstations' operating time $[32,33]$, or revisiting the disassembly tasks assignment to minimize the total idle time [34-36], cycle time [15,37,38], and the number of direction changes [39] that are the considered utilization-based operational measures. To further improve the efficiency of disassembly operations, other studies suggested priority-based approaches-for example, early removal of valuable high-demand parts $[27,40,41]$, easily accessible parts $[16,18]$, and the parts that require longer disassembly times [42]. Environment-friendly considerations were more recently incorporated to improve operational sustainability-for example, by early removal of hazardous components $[27,31,40,43]$ and maximizing $\mathrm{CO}_{2}$ saving [44]. For a comprehensive review of the DLBPs, we refer readers to the most recent surveys by [19] and [45].

Mainstream DLBPs are aimed at minimizing the total number of workstations, idle times, and the early removal of hazardous parts [19]. In disassembly operations with no restrictive precedence instructions on the sequence of the tasks, the scheduler may have no basis for deciding which task should be executed first if only tangible operational measures such as cost and time are considered. Less-tangible aspects such as the interdependencies between the tasks can make a difference, in particular, when detecting outlier tasks helps alleviate their negative influence on other tasks' performance [46]. The extant disassembly literature does not account for the possible correlations between tasks. Task correlation refers to the situation when the state of one task imposes an influence on that of the next task(s). Maximizing the degree of tasks' positive correlation is, hence, of great relevance for improving the efficiency of disassembly operations, which, in some cases, may have implications for the safety of operators; this consideration has been largely neglected in the literature.

The authors of [21] implicitly addressed the task correlation considering their processing times but did not address the degree of task correlation as an explicit optimization criterion. Processing time is not the only operational parameter that is influenced by the degree of task correlations, an indirect approach may not be effective for addressing all of the impacts of total relatedness of the disassembly operations. Inspired by the mentioned research gap, this study puts forward a two-fold contribution to waste management research. An extended Integer Nonlinear Programming (INLP) formulation to the Disassembly Line Balancing Problems with Correlated Tasks (DLBP-CT) is first proposed that addresses the industrial disassembly cases where correlated tasks are prevalent, e.g., WEEE. The Adaptive Genetic Algorithm (AGA) is then developed to efficiently solve this Non-deterministic Polynomial-time- (NP-) hard problem. An industry case example is provided to evaluate 
the practicality of the developed approach. Finally, sensitivity analysis is conducted to shed light on the operational aspects of the disassembly procedure.

The remainder of this article begins with presenting the methodological tools developed in the present study, including the mathematical formulation of the problem and the solution algorithm in Section 2. Numerical analysis is presented in Section 3, which is followed by practical implications from the results. Finally, Section 4 concludes this research and provides insights for possible future works.

\section{Proposed Methods}

\subsection{Problem Description}

Proper disassembly of WEEE items consists of extracting the components and subcomponents in a way that they can be reused, recycled, or discarded safely and soundly. Given the complexities involved in the disassembly processes, the best operational plan keeps the overall disassembly costs, which comprises the time, labor, and tooling expenses, at their lowest while ensuring the effectiveness of the operations. Notably, considering the degree of task correlation imposes a direct influence on the disassembly costs, i.e., changing the execution time and intangible operational aspects that may change depending on the type of correlation. Let $G=(V, A)$ represent a graph with the vertices, $V$, showing the state of the elements and the arcs, $A$, signifying the disassembly tasks. The state transition from one layer to another happens when a disassembly task takes place. In this definition, the source vertex of $G$ denotes a complete item, and the last layer vertices specify the components and subcomponents resulting from the disassembly process. Finally, a particular task can be one of the alternatives in different stages of the disassembly process, and the associated cycle time is assumed to be deterministic with negligible variation across the stages.

The tasks can be either correlated or unrelated [47]. Maximizing the degree of task correlation in the objective function of the optimization problem helps improve the efficiency of disassembly operations by sequencing similar tasks together. Informed positioning of the outlier (unrelated) tasks minimizes their impairing effect on the performance of other tasks. The number of connecting lines between the disassembly tasks in the relationship diagram is used for defining the degree of relevance, $\alpha$; the more the connections that exist between two tasks, the higher will be the overall correlation degree. Overall, the goal is to find the best set of disassembly tasks (i.e., separating two components or one component from the frame) and assignments to maximize the degree of task correlation and minimize the number of workstations.

\subsection{Mathematical Formulation}

Extending the formulation developed by [48], this study proposes a new INLP formulation to DLBP-CT based on the notations listed in Table 1.

Table 1. Mathematical notations.

\begin{tabular}{cc}
\hline Symbol & Description \\
\hline$j, h$ & Task index $j, h \in\{1,2, \ldots, n\}$ \\
$i, v$ & Workstation index $i, v \in\{1,2, \ldots, m\}$ \\
$d$ & Dummy task index $d \in\{1,2, \ldots, D\}$ \\
$n$ & Number of disassembly tasks to be processed \\
$m$ & Number of disassembly workstations \\
$t_{j}$ & Processing time of task $j$ \\
$r_{j h}$ & The relation between tasks $j$ and $h$ \\
$X_{j i}$ & Binary variable: $=1$ if task $j$ is assigned to workstation $i ;=0$, otherwise. \\
$Y_{i}$ & Binary variable: $=1$ if workstation $i$ is active; $=0$, otherwise. \\
$Z_{j}$ & Binary variable: $=1$ if task $j$ is executed; $=0$, otherwise. \\
\hline
\end{tabular}


In addition to the above notations, the artificial set $A_{d} \in\{1,2, \ldots, D\}$ is defined to specify a dummy node with $P\left(A_{d}\right)$ and $S\left(A_{d}\right)$ being the predecessor and successor, respectively. For the sake of simplicity, $P\left(A_{d}\right)$ and $S\left(A_{d}\right)$ for task $j$ are represented by $P_{j d}$ and $S_{j d}$, respectively. We now elaborate on the formulation.

$$
z=\sum_{i=1}^{m} Y_{i}-\left(\sum_{j=1}^{n} \sum_{h=1, j \neq h}^{n} \sum_{i=1}^{m} r_{j h} \times X_{j i} \times X_{h i}\right)
$$

Subject to:

$$
\begin{gathered}
\sum_{j=1}^{n} S_{j 1} \times Z_{j}=1 \\
\sum_{j=1}^{n} S_{j d} \times Z_{j}=\sum_{j=1}^{n} P_{j d} \times Z_{j} ; \forall d \in\{2,3, \ldots, D\} \\
\sum_{i=1}^{m} X_{j i}=Z_{j} ; \forall j \in\{1,2, \ldots, n\} \\
\sum_{j=1}^{n} \sum_{i=1}^{m} P_{j d} \times X_{j i} \geq \sum_{j=1}^{n} S_{j d} \times X_{j v} ; \forall v \in\{2,3, \ldots, m\}, \forall d \in\{2,3, \ldots, D\} \\
\sum_{j=1}^{n} X_{j i} \times t_{j} \leq T \times Y_{i} ; \forall i \in\{1,2, \ldots, m\} \\
Y_{i+1} \leq Y_{i} ; \forall i \in\{1,2, \ldots, m\} \\
X_{j i} \in\{0,1\}, \forall j \in\{1,2, \ldots, n\}, \forall i \in\{1,2, \ldots, m\} \\
Y_{i} \in\{0,1\}, \forall i \in\{1,2, \ldots, m\} \\
Z_{j} \in\{0,1\}, \forall j \in\{1,2, \ldots, n\}
\end{gathered}
$$

The objective function in Equation (1) minimizes the difference between the number of workstations and the overall correlation between tasks; this is regarded as the fitness value in the solution procedure. Equations (2) and (3) ensure that there is one and only one disassembly task to every node. Equation (4) ensures that every selected disassembly task is assigned to exactly one workstation. Constraint (5) establishes the prior relationship between the disassembly tasks and ensures that the succeeding disassembly task is not assigned to a workstation with an index smaller than that of the predecessor task. Constraint (6) limits the cycle time, ensuring that the total disassembly processing time of every workstation is less than a certain threshold, $T$. Constraint (7) guarantees the continuity of the tasks. Finally, Constraints (8) specify that the decision variables are binary.

\subsection{Solution Method}

DLBP and its derivatives are NP-hard and cannot be solved using exact methods when dealing with moderately and highly complex products [49]. Metaheuristics are viable options for finding (near-) optimum solutions to the DLBPs efficiently. Nature-inspired metaheuristics have been widely applied for solving combinatorial optimization problems [50]. The proven track record of GAs driven by strong global search capabilities [51] has encouraged us to adapt it for the disassembly line balancing context. The computational procedure of the Genetic Algorithm (GA) is inspired by the idea that the fittest individuals are more likely to make it through the next generations; this procedure is based on an evolutionary process that seeks to improve the initial solutions through crossover, mutation operators, and replacing the weak solutions with stronger offspring to form the new generations.

Despite its merits, the classic GA is susceptible to early convergence and getting trapped in local optimality. This shortcoming is alleviated in the modified algorithm, AGA, 
by adjusting the crossover and mutation rates within a two-phase procedure. Phase I comprises the following steps:

(1) Select a feasible initial disassembly path;

(2) Encode its chromosome considering the priority rule method;

(3) Initialize the disassembly groups.

Phase II consists of seven steps to find the (near-) optimum operational setting:

(1) Decoding procedure;

(2) Calculate the fitness value of the resulting solution;

(3) Selecting the fittest portion of the population for mating;

(4) Apply the Roulette Wheel Selection mechanism to select the best parent solutions;

(5) Apply the crossover mechanism for generating offspring;

(6) Apply the mutation mechanism on random offspring;

(7) Check for the stopping condition.

The computational steps under each phase are detailed below.

Phase I. The first phase consists of selecting an initial disassembly path from the set alternatives that disassemble the product into the core components. The "OR" condition is used to define the situations where there are alternative tasks to a particular step of the disassembly procedure. This situation is distinguished with an arc showing that the operator should select one of the several disassembly directions. Alternatively, arrows without a connecting arc specify the "AND" condition where the tasks in a certain disassembly step should be executed simultaneously. The exemplary disassembly diagram shown in Figure 1 is used to illustrate how the initial path should be chosen. In this diagram, the artificial node, A1, represents the commence of disassembly operations. An OR condition follows, showing that the operator should decide to dismantle B1, B2, or B3; artificial nodes follow the selected node. If B1 is selected, the subsequent artificial nodes A2 and A3 come next because the AND condition urges that both respective tasks should be executed. Following a similar approach for the rest of the path, there are various alternatives to make a complete solution, some of which are $\Pi_{1}=1,4,5,9,11,13,14,17,18,19,20,21,22$, $\Pi_{2}=1,4,6,9,12,13,18,19,20,22, \Pi_{3}=2,6,11,17,20$, and $\Pi_{4}=3,7,8,12,13,15,16,20,22$.

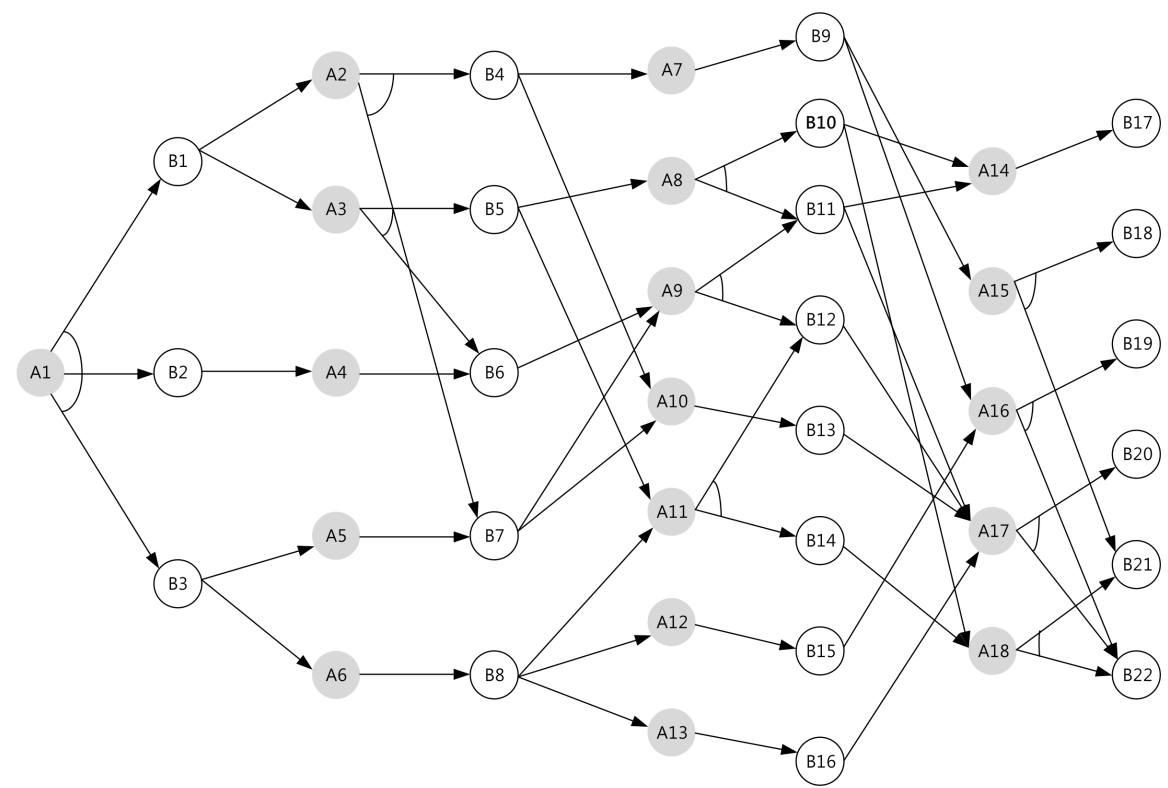

Figure 1. An illustrative example of a disassembly path for Phase I of the line planning framework.

The selected disassembly path should be then allocated to the workstations adhering to the precedence rules and the cycle time constraints. The encoding system of GAs depends on the type of the decision variables, which are overall categorized into binary, real-number encoding, integer, or literal permutation and the general data structure encod- 
ing [52]. Given the nature of the problem and considering the precedent relation rules, an integer permutation structure is used to encode the sequence arrays to show the order of disassembly tasks and their allocation to the workstations. The sorting procedure consists of the following steps:

Step 1. Create an empty sequence array.

Step 2. Select a task that has no predecessors or a task that has all its AND predecessors and at least one of its OR predecessors already in the sequence array. Then, add the selected task into the array sequence; this is to ensure that the precedence constraint is not violated.

Step 3. Cross the assigned disassembly task out from the disassembly diagram and return to the second step; continue selecting the uncrossed tasks that follow the current partial solution until the disassembly path list is complete.

Given the illustrative example in Figure 1, the process of preparing the sequence arrays is as follows. First, a path list from the disassembly diagram is selected, e.g., $\pi=[1,4,5,9,10,13,14,17,21,22]$. Next, random numbers are generated for every task; that is, $\pi=[1: 0.35,4: 0.97,5: 0.95,9: 0.49,10: 0.80,13: 0.25,14: 0.76,17: 0.91,21: 0.42,22: 0.15]$. In this example, the disassembly task B1 is the first to assign to the sequence array, $S A^{\prime}=[B 1]$, because B1 does not have any precedents and is not constrained by a random value rule for OR conditions. B1 is now crossed out from the disassembly path list. Given B1 as the precedent in the sequence array and the resulting AND condition, the next step is to proceed with B4 and B5 because they are associated with greater random values in $\prod_{r n d}$ compared with B7 and B6, respectively. B6 and B7 are now crossed out from the disassembly path. This procedure continues until a complete sequence array has resulted.

Phase II. Given the resulting sequence array from Phase I, the optimization algorithm, AGA searches for the (near-) optimum solution. The computational steps are described below.

Step 1. Decoding procedure.

Step 1.1. Determine whether the sequence array is empty; an empty array demonstrates that the disassembly task allocation is completed, and the algorithm can proceed to step 2; otherwise, proceed to Step 1.2.

Step 1.2. Calculate the overall cycle time of the existing sequence array; if it does not exceed the cycle time threshold, proceed to Step 1.3; otherwise, assign the new task to the next workstation. Create a new workstation and update the total number of workstations if all the existing workstations are fully occupied.

Step 1.3. Assign the disassembly task in the sequence array to the workstations considering the task sequence and cycle time constraints.

Step 1.4. Update the sequence array by removing the assigned task from the list.

Step 2. Calculate the fitness value of the resulting solution, which is the difference between the number of workstations and the overall correlation between the tasks. Since two objectives have different dimensions, the normalized values are used as the fitness value; the fitness value is then converted to the real values after the end of the last iteration.

Step 3. To improve the solution quality across generations, the fittest parents should be selected for the mating process. For this purpose, N/2 of all individuals with the best performance, objective function, values are kept, and the rest will be replaced by the offspring.

Step 4. Apply the Roulette Wheel Selection mechanism to select parents from the resulting set of $N / 2$ individuals. Given the individual fitness values, calculate the overall value using $F_{\text {overall }}=\sum_{i=1}^{p o p_{\text {size }}} F(i)$. Normalize the individual's fitness value by dividing it by $F_{\text {overall }}$; sort the population on an ascending basis based on the normalized values, where the last value in the list is associated with the individual with the best performance. Generate random numbers using a uniform distribution, $r \sim U(0,1)$. Select the $i$ th solution if $q_{i-1}<r<q_{i}$. 
Step 5. Crossover and mutation are GA's major operators for exploring the solution space by generating new solutions, offspring. The decision on the crossover type depends on the nature of the problem and the encoding approach (see [53]). Double-point crossover is applied to generate feasible sequence arrays from the selected parents in Step 4. After applying the crossover, the resulting offspring is checked for feasibility. If the new solution is not feasible, discard it. Return to Step 4, if there are not enough (N/2) offspring to fill the population. Otherwise, proceed to Step 6 .

Step 6. A total of $m_{\text {rate }} \times(N / 2)$ should be randomly selected from the set of offspring to be mutated. A swap mutation operator is applied to some of the offspring resulting from Step 5 depending on the mutation rate. Overall, the mutation increases the diversity of the individuals and reduces the odds of getting trapped in local optimality. Given that the population differs across generations, AGA adjusts the crossover (c_rate) and mutation ( $m$ _rate) rates to maintain the diversity of the population; the average fitness value of the current generation individuals determines this change. That is, the crossover rate increases according to the crossover rate interval (c_interval), and the mutation rate decreases according to the mutation rate interval ( $m$ interval).

Step 7. Check for the stopping condition; terminate the algorithm if the condition is met; otherwise, return to Step 2. The number of generations (gen) is decided as the termination condition [54].

\section{Numerical Results}

This section investigates the usefulness of the proposed disassembly line balancing approach. The solution algorithm is coded and compiled using MATLAB on a personal computer with the following specs: Intel ${ }^{\circledR}$ Core $^{\mathrm{TM}}$ i7-6700 CPU 3.4 GHz, 4 GB of RAM, and Windows 10 operating system. We now elaborate on the pilot test, the data set description, and the validation procedure before analyzing the results.

\subsection{Parameter Calibration}

The efficiency and effectiveness of metaheuristics are dependent on the algorithm parameter. This subsection finds the best algorithm setting before proceeding to the final experiments. The computational parameters of AGA are population size, crossover rate, crossover rate interval, mutation rate, and mutation rate interval. The population size determines the exploration width of the algorithm. The crossover and mutation rates impact the exploration depth, and the corresponding intervals control the extent of an increase or decrease in the crossover and mutation rates within the next moves. The response surface method with the Box-Behnken design framework [55] is employed to design the calibration experiments. Box-Behnken is a multi-level approach for evaluating the effects of a set of parameter changes, in this study to analyze the performance of AGA. The parameter levels provided in Figure 2a are considered to conduct the calibration tests. The average response values of 10 replications are considered to analyze the response surfaces. As shown in Figure 2b, the optimal setting obtained through the calibration test is characterized by population size of 200 , crossover rate of 0.4949 , crossover rate change of 0.4141 , the mutation rate of 0.0657 , and mutation rate change of 0.0717 . 


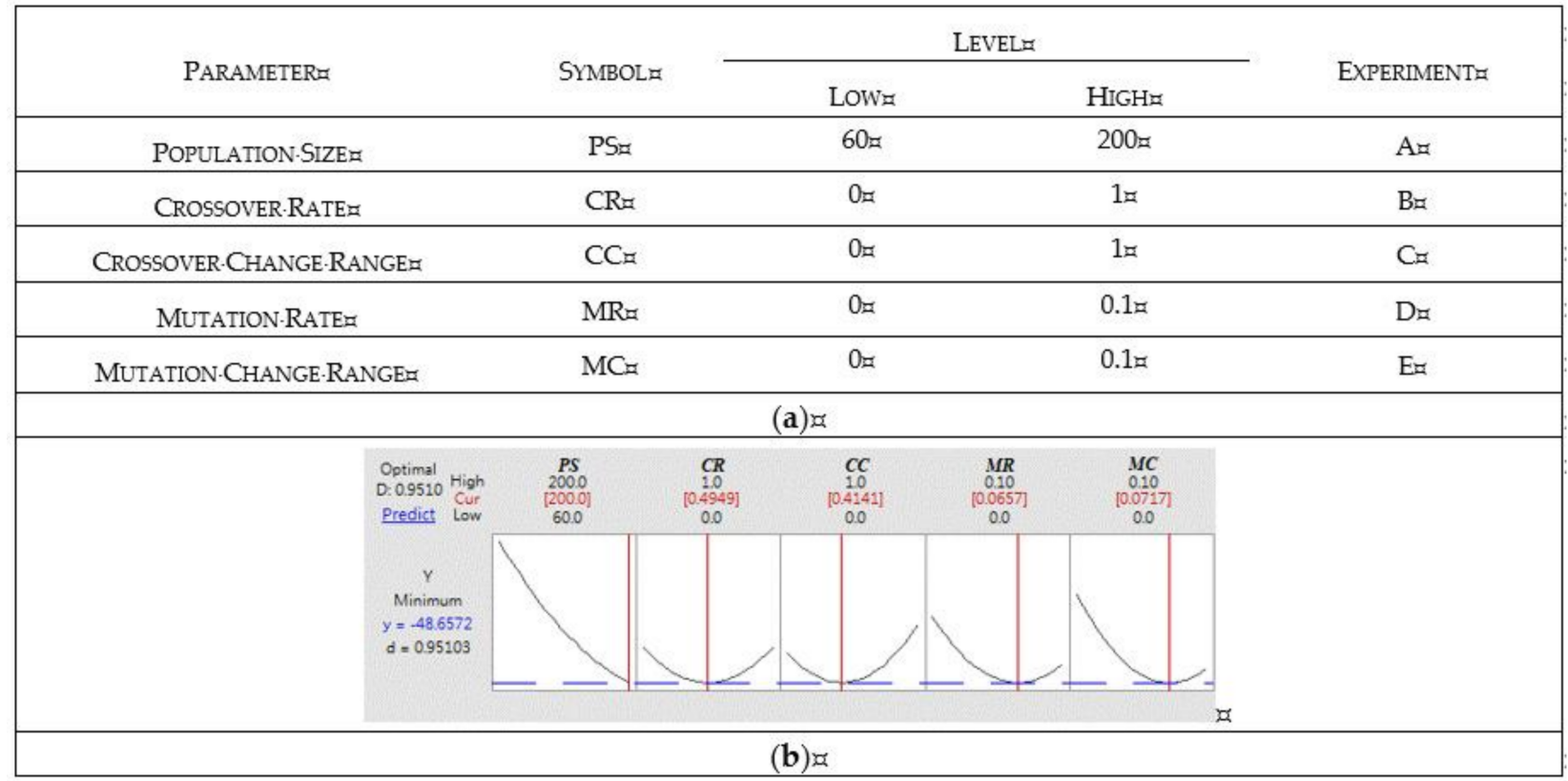

Figure 2. Algorithm parameter calibration: (a) factor levels, (b) response analysis.

\subsection{Validation}

The small-scale test instances presented in Figure 2 are considered for validation. The exemplary cases are designed to show that an increase in the problem size (i.e., the number of tasks) results in an exponential growth in problem complexity. At the same time, manually solving these test instances helps examine the correctness of the mathematical formulation and the developed algorithm. The exemplary instances include 10, 12, 14, and 15 disassembly tasks, respectively, with a processing time of 30 . The tasks' correlation is defined considering a relation index, $(i, h)=\alpha$, where $\alpha=1,3,5$ demonstrates slight, moderate, and high relevance between tasks $i$ and $h$, respectively. Let consider the instance with 15 assembly tasks; the disassembly tasks 4, 9, 18, and 25 assigned to workstation 2 have a correlation degree of $(4,9)+(4,18)+(4,25)+(9,18)+(9,25)+(18,25)=28$. These instances are solved using the Exact optimizer (Gurobi) and the AGA; results are compared in Table 2. The correlation values for instances Figure $3 a-d$ are 16, 32, 52, and 55, respectively. AGA yields the same results in a small fraction of the time required by the exact solver. Table 2 shows that the CPU time has increased exponentially with an increase in problem size. In this situation, the exact solvers in the commercial solvers, such as the Gurobi optimizer, cannot obtain an exact solution to larger instances within a reasonable computational time.

Table 2. Optimal values for the small-size test instances using an exact method.

\begin{tabular}{|c|c|c|c|c|c|c|c|c|}
\hline \multirow{2}{*}{ Ins. } & \multirow{2}{*}{$N$} & \multirow{2}{*}{$W$} & \multicolumn{2}{|c|}{ Exact Optimizer } & \multicolumn{3}{|c|}{ AGA } & \multirow{2}{*}{ Correlation } \\
\hline & & & Objective Value & CPU Time & Min & Ave & $\operatorname{Max}$ & \\
\hline I & 10 & 6 & -10 & 1.86 & -10 & -10 & -10 & 16 \\
\hline II & 12 & 6 & -26 & 34.2 & -26 & -26 & -26 & 32 \\
\hline III & 14 & 6 & -46 & 819.47 & -46 & -46 & -46 & 52 \\
\hline IV & 15 & 6 & -49 & 8928.8 & -49 & -49 & -49 & 55 \\
\hline
\end{tabular}

N: number of tasks; $W$ : number of workstations. 


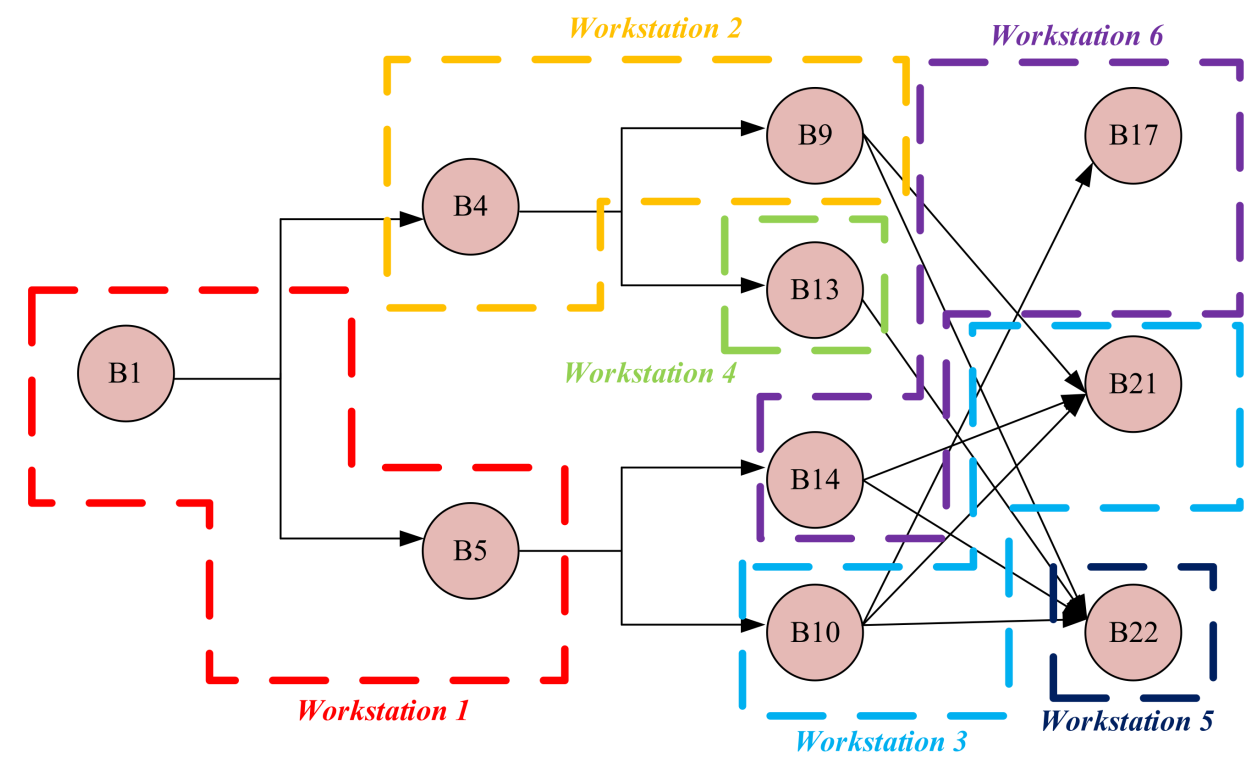

(a)

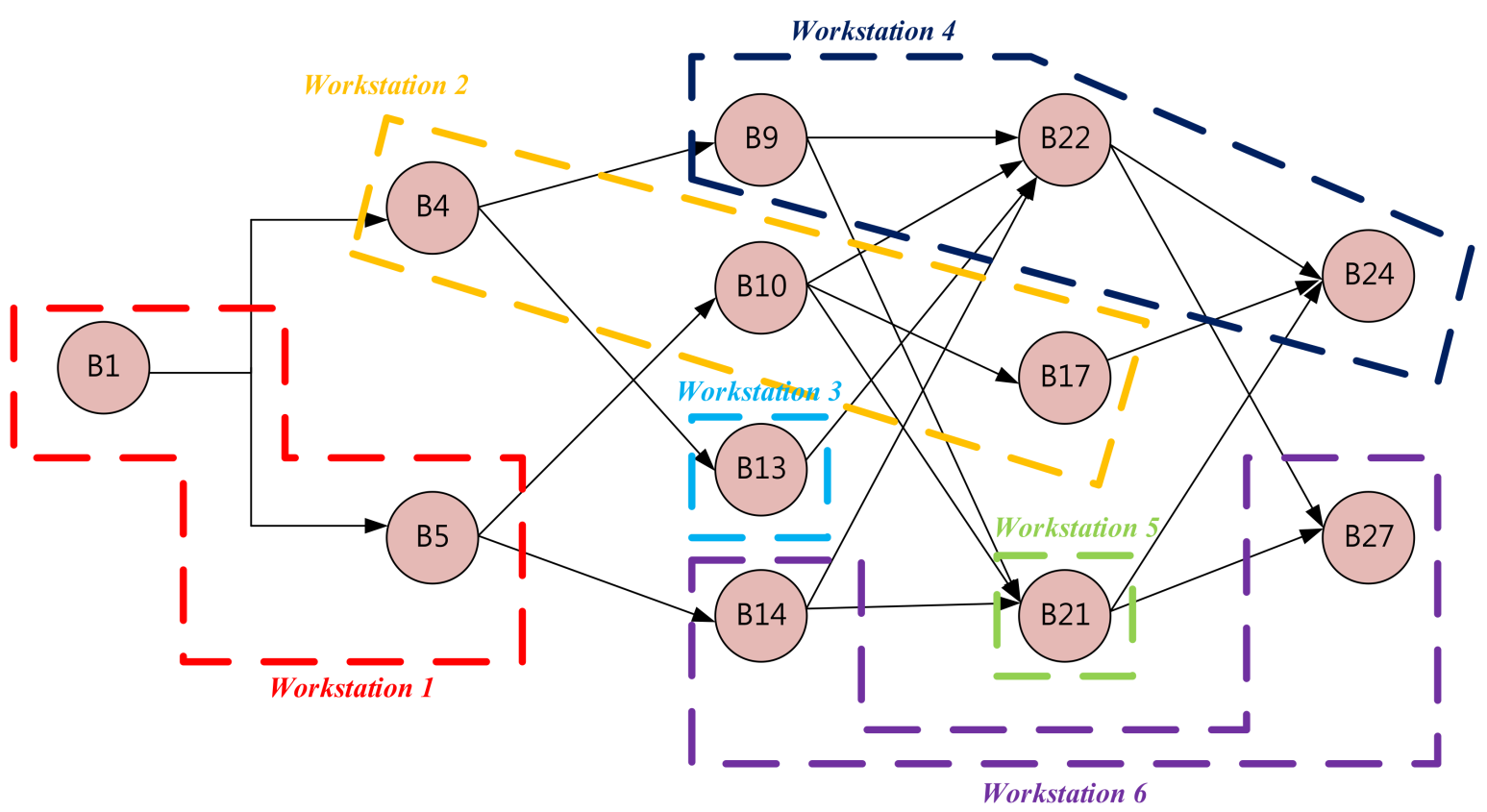

(b)

Figure 3. Cont. 


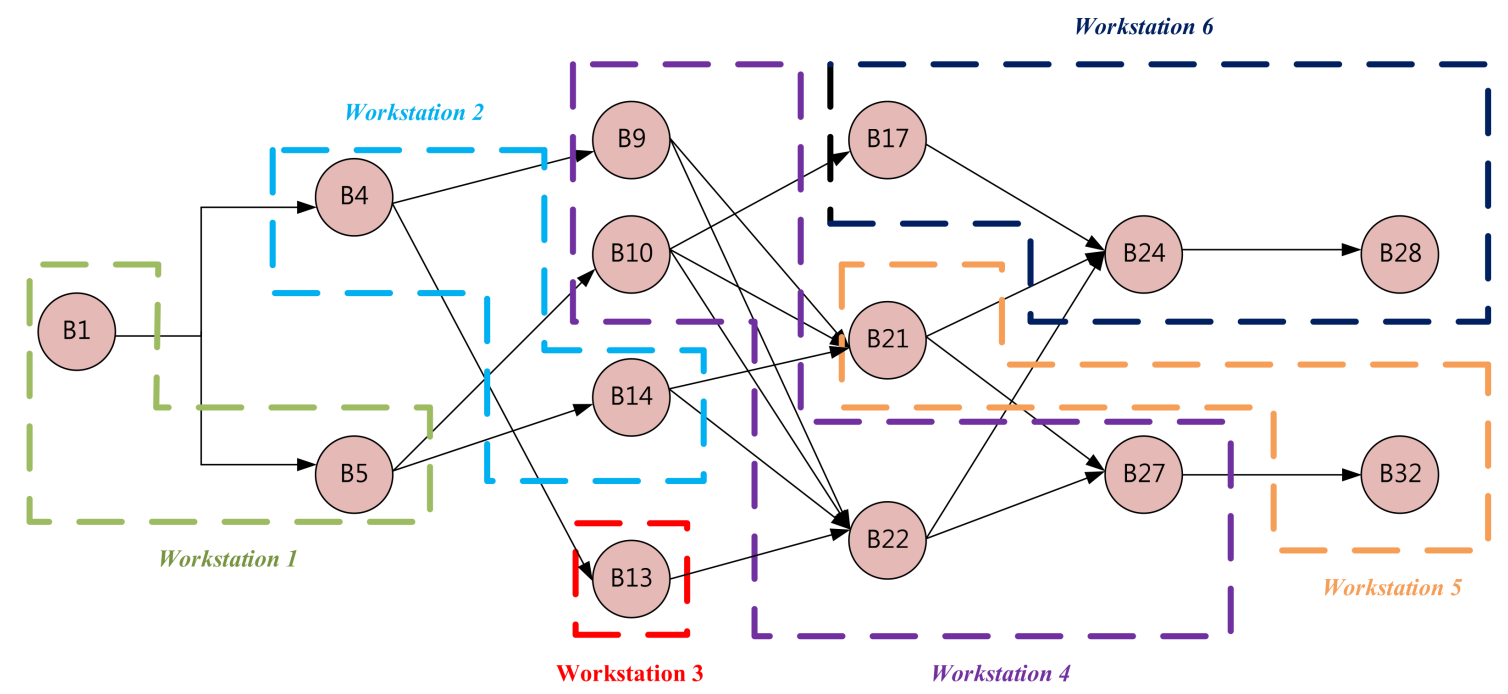

(c)

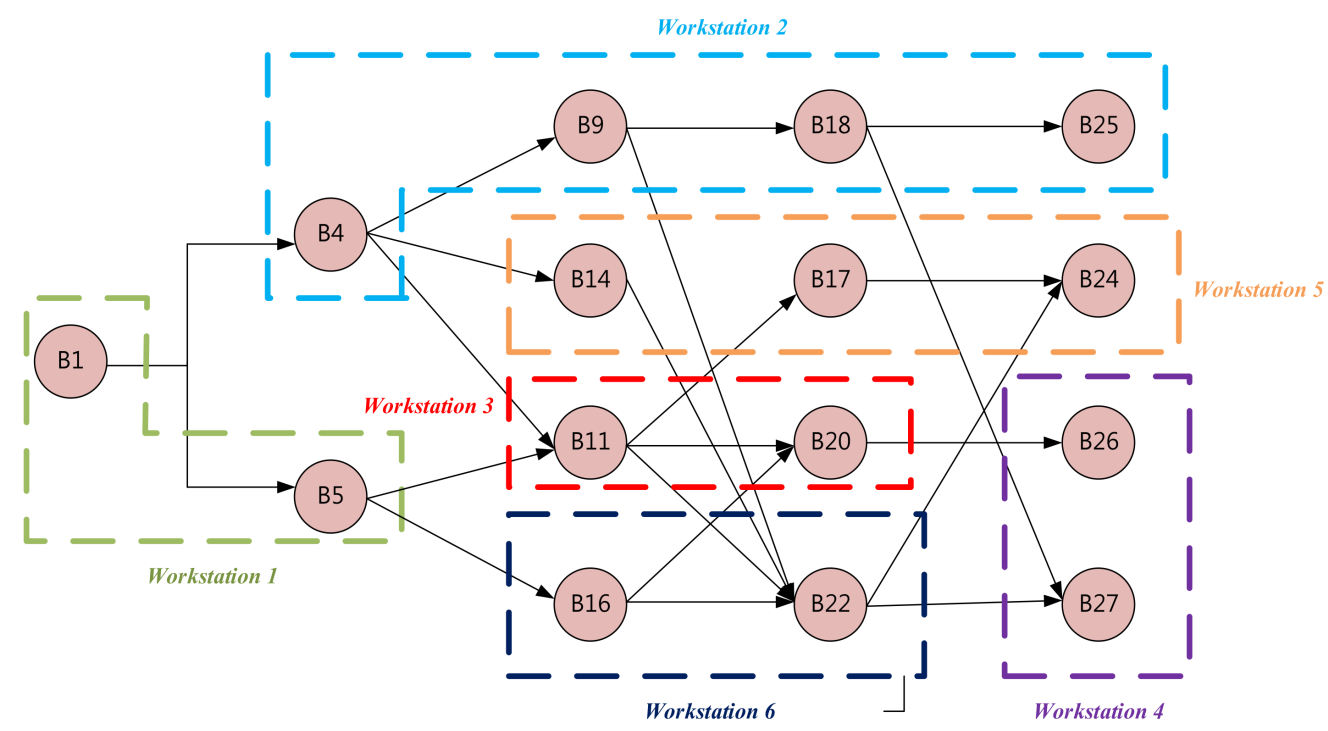

(d)

Figure 3. Disassembly diagram of the small-size test instances. (a) instance 1; (b) instance 2; (c) instance 3; (d) instance 4 .

\subsection{Case Study}

An industrial disassembly case example from consumer electronics is presented to evaluate the applicability of the developed optimization approach. Producing every additional unit of electrical and electronic equipment has degradation effects for the environment. In the particular case of producing mobile phones, the use of non-renewable earth elements, such as cobalt [56,57], has long-term consequences for the sustainability of the consumer electronics sector. Integrating the concept of task correlation can improve the efficiency of disassembly operations, which facilitates the extraction of such elements from electronics waste. Additionally, considering task correlations may help to extract such elements with 
fewer degradation effects. Other precious metals, such as cerium, europium, neodymium, terbium, and yttrium, used to produce mobile phones can have toxic effects on the disassembly operators if not disassembled properly. On top of that, the culture of the yearly switch of mobile phones leads to an overflow of this electronic waste, which is, in some cases, is handled inappropriately. For example, destruction and landfill of such products may impose negative impacts on the environment and public health by generating hazardous waste and squandering materials in the soil [58]. Informed disassembly of mobile phones is, therefore, important to help increase the recycling of end-of-life items in a sound and safe way.

The studied mobile phone comprises five main parts: shell (the platform on which the parts are attached), battery (power source), circuit board (the part responsible for the electronics operations), screen (display), and the antenna, which includes $3 \mathrm{G}, \mathrm{Wi}-\mathrm{Fi}$, and other wireless modules. The required disassembly operations are detailed in the Appendix A Table A1, which comprises a total of 52 tasks. Given the design characteristics of the device, some components are arranged in a stacked manner to fit into the small compartment and some parts/components must be handled together during the disassembly operations to avoid problems. That is, the disassembly must be carried out in an informed order, which is shown in the precedence diagram in Figure 4.

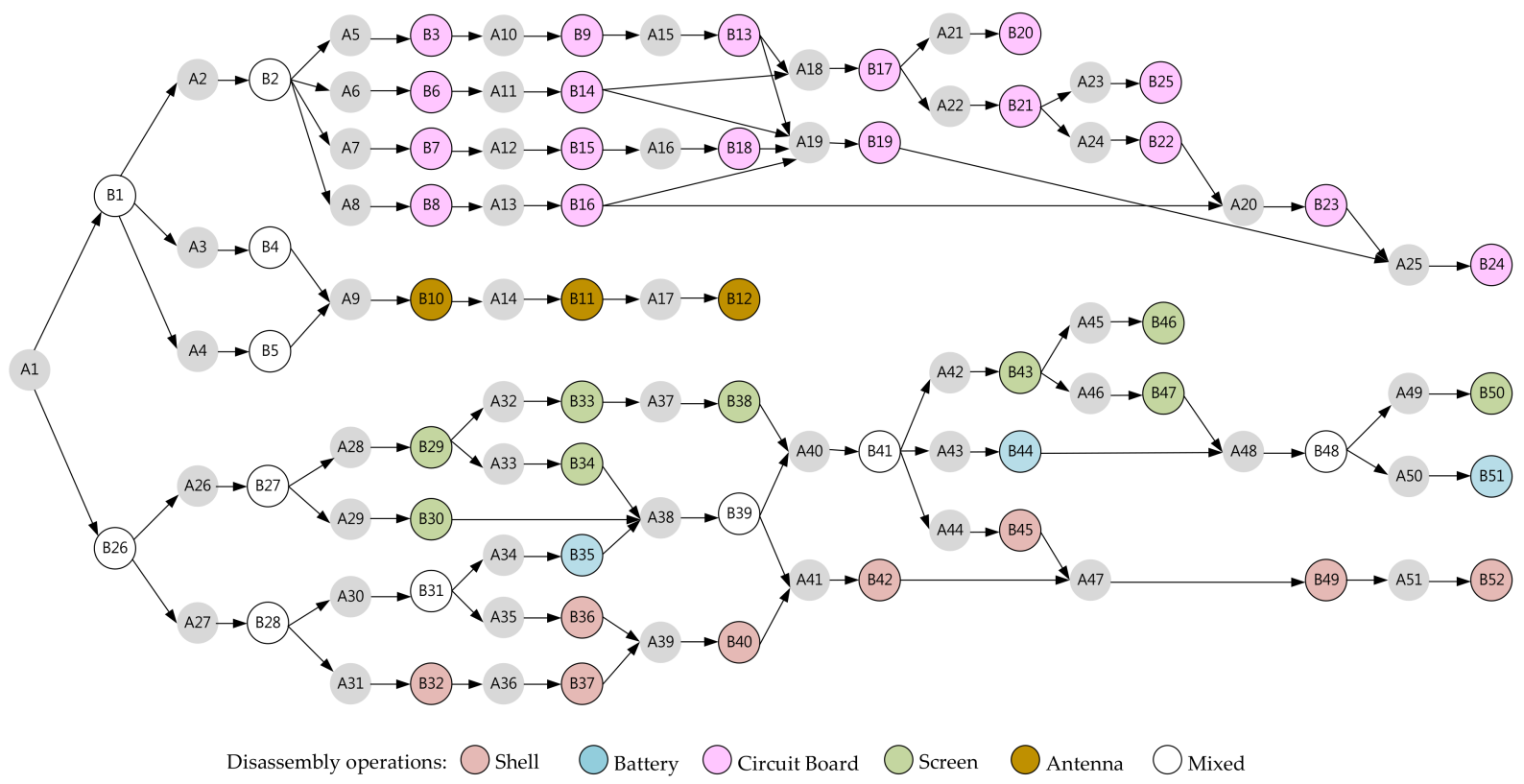

Figure 4. Disassembly chart of the studied mobile phone.

The cycle time is estimated as the summation of the longest disassembly working time and the average disassembly working time, which is $20+10=30 \mathrm{~s}$. Given the parameters determined in Section 3.1, the results obtained by AGA are converged after 100 iterations. Results are reported in Table 3, where the disassembly operations are balanced in nine workstations with a total processing time of $238 \mathrm{~s}$, correlation of 102 , and a utilization rate of more than 88 percent. 
Table 3. Numerical results for disassembly of the case example.

\begin{tabular}{ccccc}
\hline Workstation & Tasks & Processing Time (s) & Correlation & Utilization (\%) \\
\hline 1 & $1,2,3,6$ & 29 & 26 & 96.67 \\
2 & $4,5,14$ & 29 & 3 & 96.67 \\
3 & 8,16 & 26 & 5 & 86.67 \\
4 & $9,13,17$ & 29 & 15 & 96.67 \\
5 & 20 & 15 & 0 & 50 \\
6 & $21,22,23$ & 30 & 15 & 100 \\
7 & 7,15 & 22 & 5 & 73.33 \\
8 & $18,19,24$ & 28 & 15 & 93.33 \\
9 & $10,11,12,25$ & 30 & 18 & 100 \\
Overall & & 238 & 102 & 88.15 \\
\hline
\end{tabular}

Compared with the situation where correlation is not considered, the related disassembly operations are performed together; that is, tasks with high correlation are configured on the same workstations as much as possible to reduce the completion time adhering to the precedence restrictions. It is worthwhile mentioning that 'zero' correlation is because workstation 5 in Table 3 has been assigned only one task, while the correlation can exist in case of having two or more tasks. This has resulted in a low utilization rate when compared with other workstations.

Next, sensitivity analysis is conducted to explore the impact of parameter changes on the planning outcomes and shed light on the practical implications of the optimization approach. First, the impact of changes in the relationship between tasks is examined. Considering high-, moderate-, and low-correlation, alpha values are set to $\alpha=1,3,5$, respectively. To understand whether the magnitude of relation indices influences the optimization outcomes, the associated numbers are changed to $\alpha=10,30,50$ and $\alpha=100,300,500$ to explore the possible changes in the number of workstations and the degree of relevance. The numerical outcomes are summarized in Table 4, followed by the resulting workstation configurations shown in Tables 5 and 6. Evidently, there is no meaningful difference between the fitness values and the overall correlation after converting it to the base scale. Therefore, the changes in the scale of the relation index have no significant impact on the optimization outcomes.

Table 4. Results analysis over the relation index changes.

\begin{tabular}{cccc}
\hline Relation Index & Number of Workstations & Correlation & Fitness Value \\
\hline $1,3,5$ & 9 & 102 & -93 \\
$10,30,50$ & 9 & 1020 & -1011 \\
$100,300,500$ & 9 & 6400 & -6391 \\
\hline
\end{tabular}

Table 5. Sensitivity analysis considering $\alpha=10,30,50$ and $\alpha=1,3,5$.

\begin{tabular}{cccccc}
\hline \multirow{2}{*}{ Station } & \multicolumn{2}{c}{ Task Assignment } & \multicolumn{3}{c}{ Overall Correlation } \\
\cline { 2 - 6 } & $\boldsymbol{\alpha}=\mathbf{1 0 , 3 0 , 5 0}$ & $\boldsymbol{\alpha}=\mathbf{1 , 3 , 5}$ & $\boldsymbol{\alpha}=\mathbf{1 0 , 3 0 , 5 0}$ & Revised & $\boldsymbol{\alpha}=\mathbf{1 , 3 , 5}$ \\
\hline 1 & $1,2,7,3$ & $1,2,3,6$ & 260 & 26 & 26 \\
2 & 6,14 & $4,5,14$ & 50 & 5 & 3 \\
3 & $5,4,10$ & 8,16 & 110 & 11 & 5 \\
4 & 8,16 & $9,13,17$ & 50 & 5 & 15 \\
5 & $9,13,17$ & 20 & 150 & 15 & 0 \\
6 & 20 & $21,22,23$ & 0 & 0 & 5 \\
7 & $21,22,23$ & 7,15 & 150 & 15 & 15 \\
8 & $25,11,12,15$ & $18,19,24$ & 100 & 10 & 18 \\
9 & $18,19,24$ & $10,11,12,25$ & 150 & 15 & \\
\hline
\end{tabular}


Table 6. Sensitivity analysis considering $\alpha=100,300,500$ and $\alpha=1,3,5$.

\begin{tabular}{cccccc}
\hline \multirow{2}{*}{ Station } & \multicolumn{2}{c}{ Task Assignment } & \multicolumn{3}{c}{ Overall Correlation } \\
\cline { 2 - 6 } & $\boldsymbol{\alpha}=\mathbf{1 0 0 , 3 0 0 , 5 0 0}$ & $\boldsymbol{\alpha}=\mathbf{1 , 3 , 5}$ & $\boldsymbol{\alpha}=\mathbf{1 0 0 , 3 0 0 , 5 0 0}$ & Revised & $\boldsymbol{\alpha}=\mathbf{1 , 3 , 5}$ \\
\hline 1 & $1,2,6,3$ & $1,2,3,6$ & 1600 & 26 & 26 \\
2 & $4,5,14$ & $4,5,14$ & 300 & 3 & 3 \\
3 & $9,13,17$ & 8,16 & 900 & 15 & 5 \\
4 & 8,16 & $9,13,17$ & 300 & 5 & 15 \\
5 & $21,22,23$ & 20 & 900 & 15 & 0 \\
6 & $25,10,11,12$ & $21,22,23$ & 1200 & 18 & 5 \\
7 & 7,15 & 7,15 & 300 & 5 & 15 \\
8 & $18,19,24$ & $18,19,24$ & 900 & 15 & 18 \\
9 & 20 & $10,11,12,25$ & 0 & 0 & \\
\hline
\end{tabular}

Finally, the impact of cycle time changes on the disassembly outcomes is analyzed. For this purpose, four situations with various cycle times are considered to represent more complex disassembly situations. The results are summarized in Table 7. Expectedly, the number of workstations and the objective function value show a downward trend with an increase in the cycle time. It is also observed that the degree of correlation is increased, which is because more disassembly tasks are assigned to the workstations. When the cycle time is doubled, the number of workstations is nearly half of the baseline, and the degree of relevance increased proportionately. Overall, the results confirm that the developed approach effectively minimizes the number of workstations while maximizing the degree of relevance between disassembly tasks, which, in turn, improves the overall effectiveness of disassembly operations and decreases the disassembly time.

Table 7. Sensitivity analysis considering cycle time changes.

\begin{tabular}{ccccc}
\hline Change & Cycle Time (s) & Workstations & Correlation & Fitness Value \\
\hline 1 & 30 & 9 & 102 & -93 \\
1.2 & 36 & 7 & 142 & -135 \\
1.5 & 45 & 6 & 165 & -159 \\
1.7 & 51 & 5 & 203 & -198 \\
2 & 60 & 5 & 221 & -216 \\
\hline
\end{tabular}

\subsection{Implications}

In addition to improving operational efficiency, this study has implications for addressing safety hazards in the disassembly of certain electronic wastes; some components contain hazardous materials, which can be handled in a better way such that the operator is not exposed to avoidable risks. Moreover, disassembling some parts/components in a certain order may reduce the chances of injuring the operator. Such risks can be effectively reduced by considering the interdependencies between tasks and/or parts. Taking mercury-arc rectifiers as an example, they should be handled considering different factors, one of which being the degree of task correlation. Such parts are often installed upside down in a narrow space; the weight of the material may make it crash through the glass if it is not handled cautiously. For example, the quality of the performed tasks (e.g., speed of moving the parts) and parts (e.g., their weight) may increase the risk caused by high task correlation. Injuries caused by sharp parts is another example that could be avoided considering task correlations.

From an operational perspective, one can take advantage of task correlations for more energy-efficient disassembly operations-for example, through using various directional forces (e.g., gravity) and considering various frictions when planning the disassembly sequence. From a technical perspective, considering the degree of task correlation may help extract parts with minimum damages. In so doing, some of the parts may be reused (or repurposed) in the production of new items, or they can be sold in the second-hand and spare parts market. Therefore, task correlations should be considered in the Design-for- 
Disassembly initiatives. Given the plausible increase in the flow of WEEE items in near future, such initiatives will be of even more significance in optimizing the disassembly operations; this will, in turn, benefit the broad objective of processing as much electronic waste as possible and localizing the disassembly operations considering the limitations in resources and available technologies. Finally, integrating the degree of task correlation into the disassembly process planning has implications for the repair of electronic items. Improving the efficiency of the service and repair businesses will encourage more people in the developed countries to extend the use of old items; this is in line with the principles of the circular economy (i.e., spending energy on the repair of old items to reduce the use of raw material), as well as creating local jobs.

\section{Concluding Remarks}

Disassembly is an important element of electronic waste management because of it being hazardous yet valuable with proper treatment. This research explored disassembly line balancing considering correlated tasks, which is particularly useful for the disassembly of WEEE. A mathematical formulation was put forward to minimize the number of workstations and maximize the degree of relevance between disassembly tasks. A metaheuristic algorithm, AGA, was developed to solve large-scale industrial applications of the DLBP-CT. The applicability of the proposed approach was evaluated using a real case example. We showed that AGA yields the optimum solution in a fraction of the time required by the exact solution approach for small disassembly examples. It is also confirmed that the relaxation of cycle time has a positive influence on the planning outcomes; it not only reduces the number of workstations to nearly half but also increases the overall correlation between tasks. From a solution algorithm perspective, addressing the negative correlation between tasks helps reduce the search space of the model parameters, hence improving the efficiency of the planning approach.

This research can be extended in the following directions. The first direction comes from the uncertainties in the flow of End-of-Life items, more particularly WEEE; developing integrated collection-disassembly models can improve the overall system performance. Applications of advanced communication systems can benefit waste collection. Comprehensive tracking systems can be deployed to find the End-of-Life products and send collection offers in times of having a shortage in the quantity of recyclables, which facilitates economy of scale. Second, this study is limited to the disassembly of WEEE and used one case example; future studies can extend the developed line balancing approach considering other recyclables. Additionally, joint planning of various electronic items can be modeled in a way that the items with similar (or desired) components are delivered to designated areas. For this purpose, more organizational and technical complexities might have to be considered. The third suggestion is about technical features of the metal's recovery process; the disassembly sequence should account for the location of the furnace, considering the thermodynamic equilibrium and stationary state. In this situation, additional parameters should be included in the optimization model, and measurement devices might be required for data collection. Moreover, a presentation of the potential hazards in extracting parts would be of particular interest in the waste management literature; further investigations are required to account for such features in line balancing. The fourth suggestion comes from a methodological perspective; future studies may explore the applications of many-objective metaheuristics, such as the variants of the Non-dominated Sorting Genetic Algorithm III, for solving the line balancing problems while considering a more comprehensive set of conflicting performance indicators. In so doing, one can study the interactions between the degree of task correlation and costs, as well as the safety of the operations. 
Author Contributions: Conceptualization, Y.-Y.C.; methodology, Y.-Y.C.; software, C.-Y.C.; validation, Y.-Y.C. and C.-Y.C.; formal analysis, C.-Y.L. and P.P.; investigation, P.P.; resources, C.-Y.C.; data curation, C.-Y.L.; writing—original draft preparation, P.P.; writing—review and editing, P.P.; visualization, C.-Y.L.; supervision, Y.-Y.C.; project administration, C.-Y.C. All authors have read and agreed to the published version of the manuscript.

Funding: This research received no external funding.

Acknowledgments: The publication charges for this article have been funded by a grant from the publication fund of UiT- The Arctic University of Norway.

Conflicts of Interest: The authors declare no conflict of interest.

\section{Appendix A}

Table A1. Required tasks for the disassembly of the studied device.

\begin{tabular}{|c|c|c|c|c|c|}
\hline $\begin{array}{c}\text { Disassembly Task } \\
\text { Number }\end{array}$ & $\begin{array}{c}\text { The Predecessor } \\
\text { Task (s) }\end{array}$ & $\begin{array}{l}\text { Processing Time } \\
\text { of Task (s) }\end{array}$ & $\begin{array}{c}\text { Disassembly Task } \\
\text { Number }\end{array}$ & $\begin{array}{c}\text { The Predecessor } \\
\text { Task (s) }\end{array}$ & $\begin{array}{l}\text { Processing Time } \\
\text { of Task (s) }\end{array}$ \\
\hline 1 & - & 7 & 27 & 26 & 13 \\
\hline 2 & 1 & 3 & 28 & 26 & 11 \\
\hline 3 & 2 & 4 & 29 & 27 & 5 \\
\hline 4 & 1 & 10 & 30 & 27 & 9 \\
\hline 5 & 1 & 10 & 31 & 28 & 7 \\
\hline 6 & 2 & 15 & 32 & 28 & 18 \\
\hline 7 & 2 & 15 & 33 & 29 & 2 \\
\hline 8 & 2 & 9 & 34 & 29 & 3 \\
\hline 9 & 3 & 7 & 35 & 31 & 5 \\
\hline 10 & 4,5 & 9 & 36 & 31 & 6 \\
\hline 11 & 10 & 10 & 37 & 32 & 6 \\
\hline 12 & 11 & 10 & 38 & 33 & 6 \\
\hline 13 & 9 & 9 & 39 & $30,34,35$ & 7 \\
\hline 14 & 6 & 7 & 40 & 36,37 & 15 \\
\hline 15 & 7 & 11 & 41 & 38,39 & 19 \\
\hline 16 & 8 & 10 & 42 & 39,40 & 20 \\
\hline 17 & 13,14 & 10 & 43 & 41 & 3 \\
\hline 18 & 15 & 10 & 44 & 41 & 7 \\
\hline 19 & $14,16,18$ & 15 & 45 & 41 & 16 \\
\hline 20 & 17 & 15 & 46 & 43 & 9 \\
\hline 21 & 17 & 20 & 47 & 43 & 9 \\
\hline 22 & 21 & 5 & 48 & 44,47 & 18 \\
\hline 23 & 16,22 & 5 & 49 & 42,45 & 14 \\
\hline 24 & 19,23 & 3 & 50 & 48 & 5 \\
\hline 25 & 21 & 4 & 51 & 48 & 7 \\
\hline 26 & - & 8 & 52 & 49 & 10 \\
\hline
\end{tabular}

\section{References}

1. Chaudhary, K.; Vrat, P. Case study analysis of e-waste management systems in Germany, Switzerland, Japan and India: A RADAR chart approach. Benchmarking Int. J. 2018, 25, 3519-3540. [CrossRef]

2. Eurostat Waste. Available online: https:/ / ec.europa.eu/eurostat/web/waste/data (accessed on 11 January 2022). 
3. Otsuki, A.; La Mensbruge, L.D.; King, A.; Serranti, S.; Fiore, L.; Bonifazi, G. Non-destructive characterization of mechanically processed waste printed circuit boards-particle liberation analysis. Waste Manag. 2020, 102, 510-519. [CrossRef] [PubMed]

4. Pourhejazy, P.; Zhang, D.; Zhu, Q.; Wei, F.; Song, S. Integrated E-waste transportation using capacitated general routing problem with time-window. Transp. Res. Part E Logist. Transp. Rev. 2021, 145, 102169. [CrossRef]

5. Wei, F.; Zhu, Q.; Pourhejazy, P.; Liu, C. Contract vs. recruitment: Integrating an informal waste merchant to a formal collector for collection of municipal solid waste. J. Clean. Prod. 2021, 287, 125004. [CrossRef]

6. Reike, D.; Vermeulen, W.J.V.; Witjes, S. The circular economy: New or refurbished as CE 3.0?-Exploring controversies in the conceptualization of the circular economy through a focus on history and resource value retention options. Resour. Conserv. Recycl. 2018, 135, 246-264. [CrossRef]

7. Sun, Z.; Cao, H.; Xiao, Y.; Sietsma, J.; Jin, W.; Agterhuis, H.; Yang, Y. Toward sustainability for recovery of critical metals from electronic waste: The hydrochemistry processes. ACS Sustain. Chem. Eng. 2017, 5, 21-40. [CrossRef]

8. Wong, M.H.; Wu, S.C.; Deng, W.J.; Yu, X.Z.; Luo, Q.; Leung, A.O.W.; Wong, C.S.C.; Luksemburg, W.J.; Wong, A.S. Export of toxic chemicals-A review of the case of uncontrolled electronic-waste recycling. Environ. Pollut. 2007, 149, 131-140. [CrossRef]

9. Friedlander, L.R.; Weisbrod, N.; Garb, Y.J. Climatic and soil-mineralogical controls on the mobility of trace metal contamination released by informal electronic waste (e-waste) processing. Chemosphere 2019, 232, 130-139. [CrossRef] [PubMed]

10. Grant, K.; Goldizen, F.C.; Sly, P.D.; Brune, M.-N.; Neira, M.; van den Berg, M.; Norman, R.E. Health consequences of exposure to e-waste: A systematic review. Lancet Glob. Health 2013, 1, e350-e361. [CrossRef]

11. Bhandari, P. Impacts on Environment and on Human Health. In Responsible Consumption and Production; Leal Filho, W., Azul, A.M., Brandli, L., Özuyar, P.G., Wall, T., Eds.; Springer International Publishing: Cham, Switzerland, 2020; pp. 349-357, ISBN 978-3-319-95726-5.

12. Houessionon, M.G.K.; Ouendo, E.-M.D.; Bouland, C.; Takyi, S.A.; Kedote, N.M.; Fayomi, B.; Fobil, J.N.; Basu, N. Environmental Heavy Metal Contamination from Electronic Waste (E-Waste) Recycling Activities Worldwide: A Systematic Review from 2005 to 2017. Int. J. Environ. Res. Public Health 2021, 18, 3517. [CrossRef]

13. Otsuki, A.; Gonçalves, P.P.; Stieghorst, C.; Révay, Z. Non-Destructive Characterization of Mechanically Processed Waste Printed Circuit Boards: X-ray Fluorescence Spectroscopy and Prompt Gamma Activation Analysis. J. Compos. Sci. 2019, 3, 54. [CrossRef]

14. Rosa, P.; Sassanelli, C.; Terzi, S. Circular Business Models versus circular benefits: An assessment in the waste from Electrical and Electronic Equipments sector. J. Clean. Prod. 2019, 231, 940-952. [CrossRef]

15. McGovern, S.M.; Gupta, S.M. A balancing method and genetic algorithm for disassembly line balancing. Eur. J. Oper. Res. 2007, 179, 692-708. [CrossRef]

16. Güngör, A.; Gupta, S.M. Disassembly line in product recovery. Int. J. Prod. Res. 2002, 40, 2569-2589. [CrossRef]

17. Altekin, F.T.; Kandiller, L.; Ozdemirel, N.E. Profit-oriented disassembly-line balancing. Int. J. Prod. Res. 2008, 46, 2675-2693. [CrossRef]

18. Gungor, A.; Gupta, S.M. A solution approach to the disassembly line balancing problem in the presence of task failures. Int. J. Prod. Res. 2001, 39, 1427-1467. [CrossRef]

19. Özceylan, E.; Kalayci, C.B.; Güngör, A.; Gupta, S.M. Disassembly line balancing problem: A review of the state of the art and future directions. Int. J. Prod. Res. 2019, 57, 4805-4827. [CrossRef]

20. Altekin, F.T.; Akkan, C. Task-failure-driven rebalancing of disassembly lines. Int. J. Prod. Res. 2012, 50, 4955-4976. [CrossRef]

21. Liu, M.; Liu, X.; Chu, F.; Zheng, F.; Chu, C. Robust disassembly line balancing with ambiguous task processing times. Int. J. Prod. Res. 2020, 58, 5806-5835. [CrossRef]

22. Minca, E.; Filipescu, A.; Voda, A. Modelling and control of an assembly/disassembly mechatronics line served by mobile robot with manipulator. Control Eng. Pract. 2014, 31, 50-62. [CrossRef]

23. Kalaycilar, E.G.; Azizouglu, M.; Yeralan, S. A disassembly line balancing problem with fixed number of workstations. Eur. J. Oper. Res. 2016, 249, 592-604. [CrossRef]

24. Duta, L.; Caciula, I.; Patic, P.C. Column generation approach for disassembly line balancing. IFAC Pap. 2016, 49, 916-920. [CrossRef]

25. Zsigraiova, Z.; Semiao, V.; Beijoco, F. Operation costs and pollutant emissions reduction by definition of new collection scheduling and optimization of MSW collection routes using GIS. The case study of Barreiro, Portugal. Waste Manag. 2013, 33, 793-806. [CrossRef] [PubMed]

26. Gungor, A.; Gupta, S.M.; Pochampally, K.; Kamarthi, S.V. Complications in disassembly line balancing. In Environmentally Conscious Manufacturing; International Society for Optics and Photonics: Boston, MA, USA, 2001; Volume 4193, pp. 289-298.

27. Liu, J.; Wang, S. Balancing disassembly line in product recovery to promote the coordinated development of economy and environment. Sustainability 2017, 9, 309. [CrossRef]

28. Altekin, F.T. A comparison of piecewise linear programming formulations for stochastic disassembly line balancing. Int. J. Prod. Res. 2017, 55, 7412-7434. [CrossRef]

29. Habibi, M.K.K.; Battaia, O.; Cung, V.-D.; Dolgui, A. An efficient two-phase iterative heuristic for Collection-Disassembly problem. Comput. Ind. Eng. 2017, 110, 505-514. [CrossRef]

30. Ren, Y.; Yu, D.; Zhang, C.; Tian, G.; Meng, L.; Zhou, X. An improved gravitational search algorithm for profit-oriented partial disassembly line balancing problem. Int. J. Prod. Res. 2017, 55, 7302-7316. [CrossRef]

31. Ren, Y.; Zhang, C.; Zhao, F.; Tian, G.; Lin, W.; Meng, L.; Li, H. Disassembly line balancing problem using interdependent weights-based multi-criteria decision making and 2-Optimal algorithm. J. Clean. Prod. 2018, 174, 1475-1486. [CrossRef] 
32. Aydemir-Karadag, A.; Turkbey, O. Multi-objective optimization of stochastic disassembly line balancing with station paralleling. Comput. Ind. Eng. 2013, 65, 413-425. [CrossRef]

33. Wang, K.; Li, X.; Gao, L. A multi-objective discrete flower pollination algorithm for stochastic two-sided partial disassembly line balancing problem. Comput. Ind. Eng. 2019, 130, 634-649. [CrossRef]

34. Kannan, D.; Garg, K.; Jha, P.C.; Diabat, A. Integrating disassembly line balancing in the planning of a reverse logistics network from the perspective of a third party provider. Ann. Oper. Res. 2017, 253, 353-376. [CrossRef]

35. Xiao, S.; Wang, Y.; Yu, H.; Nie, S. An entropy-based adaptive hybrid particle swarm optimization for disassembly line balancing problems. Entropy 2017, 19, 596. [CrossRef]

36. Li, Z.; Kucukkoc, I.; Zhang, Z. Iterated local search method and mathematical model for sequence-dependent U-shaped disassembly line balancing problem. Comput. Ind. Eng. 2019, 137, 106056. [CrossRef]

37. Kekre, S.; Rao, U.S.; Swaminathan, J.M.; Zhang, J. Reconfiguring a remanufacturing line at Visteon, Mexico. Interfaces 2003, 33, 30-43. [CrossRef]

38. Paksoy, T.; Güngör, A.; Özceylan, E.; Hancilar, A. Mixed model disassembly line balancing problem with fuzzy goals. Int. J. Prod. Res. 2013, 51, 6082-6096. [CrossRef]

39. Zhu, X.; Zhang, Z.; Hu, J. An ant colony optimization algorithm for multi-objective disassembly line balancing problem. Zhongguo Jixie China Mech. Eng. 2014, 25, 1075-1079.

40. Jia, L.; Shuwei, W. A proposed multi-objective optimization model for sequence-dependent disassembly line balancing problem. In Proceedings of the 2017 3rd International Conference on Information Management (ICIM), Chengdu, China, 21-23 April 2017; IEEE: Piscataway, NJ, USA, 2017; pp. 421-425.

41. Xiao, S.; Nie, S.K. An improved adaptive multi-objective particle swarm optimization for disassembly line balancing problem. Int J. Res. Eng. Sci. 2017, 5, 55-61.

42. Avikal, S.; Jain, R.; Yadav, H.; Mishra, P.K. A New Heuristic for Disassembly Line Balancing Problems with AND/OR Precedence Relations. In Proceedings of the Second International Conference on Soft Computing for Problem Solving (SocProS 2012), New Delhi, India, 28-30 December 2012; pp. 519-525.

43. Bentaha, M.L.; Battaia, O.; Dolgui, A. Disassembly line balancing and sequencing under uncertainty. Procedia Cirp 2014, 15, 239-244. [CrossRef]

44. Igarashi, K.; Yamada, T.; Gupta, S.M.; Inoue, M.; Itsubo, N. Disassembly system modeling and design with parts selection for cost, recycling and $\mathrm{CO}_{2}$ saving rates using multi criteria optimization. J. Manuf. Syst. 2016, 38, 151-164. [CrossRef]

45. Laili, Y.; Li, Y.; Fang, Y.; Pham, D.T.; Zhang, L. Model review and algorithm comparison on multi-objective disassembly line balancing. J. Manuf. Syst. 2020, 56, 484-500. [CrossRef]

46. Zhang, Y.; Yeung, D.-Y. A regularization approach to learning task relationships in multitask learning. ACM Trans. Knowl. Discov. Data 2014, 8, 1-31. [CrossRef]

47. Zhang, Y.; Yeung, D.-Y. A convex formulation for learning task relationships in multi-task learning. arXiv 2012, arXiv:1203.3536.

48. Koc, A.; Sabuncuoglu, I.; Erel, E. Two exact formulations for disassembly line balancing problems with task precedence diagram construction using an AND/OR graph. IIE Trans. 2009, 41, 866-881. [CrossRef]

49. Mete, S.; Çil, Z.A.; Ağpak, K.; Özceylan, E.; Dolgui, A. A solution approach based on beam search algorithm for disassembly line balancing problem. J. Manuf. Syst. 2016, 41, 188-200. [CrossRef]

50. Mirjalili, S.; Dong, J.S.; Lewis, A. Nature-Inspired Optimizers; Springer: Berlin/Heidelberg, Germany, 2020.

51. Kerh, T.; Su, Y.-H.; Mosallam, A. Incorporating global search capability of a genetic algorithm into neural computing to model seismic records and soil test data. Neural Comput. Appl. 2017, 28, 437-448. [CrossRef]

52. Gen, M.; Cheng, R. Genetic Algorithms and Engineering Optimization; John Wiley \& Sons: Hoboken, NJ, USA, $2000 ;$ Volume 7.

53. Alabsi, F.; Naoum, R. Comparison of selection methods and crossover operations using steady state genetic based intrusion detection system. J. Emerg. Trends Comput. Inf. Sci. 2012, 3, 1053-1058.

54. Kumar, M.; Husian, M.; Upreti, N.; Gupta, D. Genetic algorithm: Review and application. Int. J. Inf. Technol. Knowl. Manag. 2010, 2, 451-454. [CrossRef]

55. Ferreira, S.L.C.; Bruns, R.E.; Ferreira, H.S.; Matos, G.D.; David, J.M.; Brandao, G.C.; da Silva, E.G.P.; Portugal, L.A.; Dos Reis, P.S.; Souza, A.S.; et al. Box-Behnken design: An alternative for the optimization of analytical methods. Anal. Chim. Acta 2007, 597, 179-186. [CrossRef]

56. Pavel, C.; Blagoeva, D.; Alves Dias, P.; Arvanitidis, N. Cobalt: Demand-Supply Balances in the Transition to Electric Mobility; EURScientific and Technical Research Reports; EUR-Scientific and Technical Research Reports Publications Office of the EU; European Commission; Joint Research Centre: Brussels, Belgium, 2018; Volume 10, p. 97710. [CrossRef]

57. Piçarra, A.; Annesley, I.R.; Otsuki, A.; de Waard, R. Market assessment of cobalt: Identification and evaluation of supply risk patterns. Resour. Policy 2021, 73, 102206. [CrossRef]

58. Pourhejazy, P. Destruction Decisions for Managing Excess Inventory in E-Commerce Logistics. Sustainability 2020, 12, 8365. [CrossRef] 